Gallardo-Saborido, E. J. (2020): Narrativas de ida y vuelta: flamenco, tauromaquia, literatura y diálogos transatlánticos. Cultura, Lenguaje y

Representación, Vol. XXIV, 75-88

ISSN $1697-7750 \cdot$ e-ISSN 2340-4981

DOI: http://dx.doi.org/10.6035/clr.2020.24.4

\title{
Narrativas de ida y vuelta: flamenco, tauromaquia, literatura y diálogos transatlánticos
}

Round trip narratives: flamenco, bullfighting, literature and Transatlantic dialogues

EMILIO J. GALLARDO-SABORIDO

ESCUELA DE ESTUDIOS HISPANO-AMERICANOS, CSIC

Artículo recibido el / Article received: 2020-03-25

Artículo aceptado el / Article accepted: 2020-07-14

RESUMEN: Esta contribución se acerca a las relaciones entre narrativa y flamenco en sendas novelas escritas por autores latinoamericanos en el primer tercio del siglo XX (Santa, 1903, del mexicano Federico Gamboa, y El embrujo de Sevilla, 1922, del uruguayo Carlos Reyles). De este modo, se atiende al uso del flamenco como marcador de la identidad andaluza y como recurso propiciador del diálogo transatlántico entre España y América Latina. Específicamente, en el caso de Gamboa se prioriza la reflexión sobre las relaciones entre masculinidad andaluza y flamenco; mientras que en el de Reyles se profundiza en las conexiones entre flamenco y religión. En fin, ambos textos se insertan y dialogan con una dilatada tradición literaria que recurre a Andalucía como cornucopia creativa, como acicate de la imaginación, al tiempo que patentizan el contemporáneo trasiego cultural entre España y América Latina, que ha tenido como puente de unión al flamenco y a los flamencos.

Palabras clave: Andalucía, Carlos Reyles, estudios gitanos, estudios transatlánticos, Federico Gamboa, flamenco, literatura latinoamericana.

ABSTRACT: This contribution approaches the relationship between narrative and flamenco in two novels written by Latin American authors in the first third of the 20th century (Santa, 1903, by the Mexican Federico Gamboa, and El embrujo de Sevilla, 1922, by the Uruguayan Carlos Reyles). In this way, the use of flamenco as a marker of Andalusian identity and as a propitiatory resource for Transatlantic dialogue between Spain and Latin America is addressed. Specifically, in the case of Gamboa, a reflection on the relationship between Andalusian masculinity and flamenco is prioritized; while in Reyles', the connections between flamenco and religion are focused. In short, both texts are inserted and dialogue with a long literary tradition that uses Andalusia as a creative cornucopia, as a stimulus to the imagination, while at the same time evidence the contemporary cultural dialogue between Spain and Latin America, which has had flamenco and flamenco musicians as a bridge. 
Key words: Andalusia, Carlos Reyles, Federico Gamboa, flamenco, Latin American literature, Romani Studies, Transatlantic Studies.

\section{INTRODUCCIÓN}

En el primer tercio del siglo XX, momento de publicación de las novelas de las que ahora nos ocuparemos, el flamenco había probado ser capaz de varios hitos nada desdeñables para un arte de raíz popular.

En primer lugar, había demostrado ser una potente fuente creativa, que había servido de inspiración a literatos y artistas (pintores, músicos, fotógrafos, cineastas, etc.) patrios y extranjeros desde, al menos, la primera mitad del siglo XIX.

En segundo lugar, y pese a las controversias que generaba y que generaría, había conseguido atraer la atención de un respetable sector académico que serviría de punta de lanza para los posteriores estudios flamencos, y donde, dada su calidad de iniciadores, merecen ser recordados nombres como los de Antonio Machado y Álvarez, y Hugo Schuchardt ${ }^{1}$.

En tercer lugar, ya había quedado patente su potencial como recurso económico, tal y como mostraba, por ejemplo, el éxito de los cafés cantantes desde las últimas décadas del XIX, y como se constataría de nuevo al iniciarse el periodo denominado ópera flamenca. Asimismo, esta significación comercial se evidenciaría desde fechas muy tempranas no sólo en los escenarios españoles, sino también americanos. ${ }^{2}$

Y, por último, a partir de la mirada romántica foránea y autóctona, se había convertido en un elemento recurrente a la hora de caracterizar lo andaluz y, por extensión, lo español.

Aunque en diferente medida, estos cuatro hitos serán abordados por los escritores que serán objeto de nuestra atención. Ambos contribuirán a la evocación del flamenco por la narrativa latinoamericana en un intercambio transatlántico similar al sufrido por la propia música flamenca en su contacto con América Latina, y que está en el origen de los denominados cantes de ida y vuelta ${ }^{3}$. Se trata de los casos del mexicano Federico Gamboa (1864-1939) y del uruguayo Carlos Reyles (1868-1938), y de sus respectivas novelas Santa (1903) y El embrujo de Sevilla (1922). Con ello unirán su voz a las controversias

11881 ha sido calificado por Gerhard Steingress como el año en que «"nació" la Flamencología» (Steingress, 1990: 10). En él se publicaron las fundacionales investigaciones Colección de cantes flamencos de Antonio Machado y Álvarez, y Die Cantes flamencos, del austriaco Hugo Schuchardt. Para una revisión discutida de algunas de las principales contribuciones bibliográficas al campo de los estudios flamencos, véase Cruces (1998).

2 Por ejemplo, véase en este sentido: Gamboa, 2016 y 2017, Ortiz Nuevo, 2019, Reyes \& Hernández, 2011.

3 Reyes y Hernández (2011: 33) problematizan la definición tradicional de esta etiqueta según la cual en ella se incluirían «aquellos palos que, habiendo llegado a tierras americanas, regresaron a España para transformarse en estilos flamencos». Aplicado este resbaladizo concepto en ocasiones de forma caprichosa a una serie de cantes (guajiras, colombianas, rumbas, milongas y vidalitas), se han olvidado en otras algunos de raíz "indiana" (fandangos, peteneras, tangos, cabales). En este sentido, Reyes y Hernández prestan atención a los casos del fandango, el zapateado o la petenera. Uno de los primeros autores que se ocupó de esta etiqueta fue Fernando Quiñones en De Cádiz y sus cantes (1974). Para una comparativa musicológica de los distintos tipos de fandangos españoles y americanos, ver Berlanga (2015). Por último, Castro dedica un artículo al zapateado (2014). Por su parte, Steingress lee la historia del flamenco desde el concepto de hibridación transcultural. De hecho, sostiene: «la aparición del género flamenco a mediados del siglo XIX muestra que la evolución de la música popular siempre estuvo sometida a múltiples influencias culturales sobrevenidas de allende los límites de su arraigo social» (2005: 121). 
intelectuales que el flamenco y el flamenquismo ${ }^{4}$ suscitaban en la península ibérica. Del mismo modo, harán un aporte significativo a la presencia del flamenco en la literatura latinoamericana, que había atraído ya la atención de, por ejemplo, Rubén Darío 5 . Igualmente, las dos novelas se complementan en cuanto a la geografía, ya que Gamboa incorpora el flamenco en una trama acaecida principalmente en la Ciudad de México; mientras que, en el caso de Reyles, es él quien realiza el viaje transatlántico - de hecho, era buen conocedor de Sevilla ${ }^{6}$ - y sitúa su acción en la capital andaluza ${ }^{7}$. Por último, pero no se trata de una cuestión menor: los dos textos gozarán de un sonado éxito al darse a conocer ${ }^{8}$.

\section{2. «QUÉ DIFÍCIL HACERLOS BAILAR!»: MASCULINIDADES ANDALUZAS Y FLAMENCO EN SANTA (1903)}

Dentro de la carrera a la perdición prostibularia de la protagonista que constituye la historia ${ }^{9}$, Gamboa inserta varios personajes españoles, pero especialmente uno de ellos

\footnotetext{
${ }^{4}$ En otro trabajo in fieri aludo al papel vertebral del escritor español Eugenio Noel a la hora de codificar en el término flamenquismo toda una serie de afanes regeneracionistas ligados a la generación del 98, de manera que en él encerrará «la raíz de la barbarie y el atraso españoles [...]. Tauromaquia, flamenco, señoritos chulos, gitanos... En todos ellos hipostasiará la pesada y oscura losa del atraso secular español». Así, en uno de los libros ligados a su campaña antiflamenca (República y flamenquismo, 1912) aseverará: «Flamenquismo quiere decir matonismo, prestancia personal exterior, andar torero, fatuidad, [...] cara gitana, [...] la lágrima cayendo en un chato de manzanilla, el ay-ay de la guitarra, [...] el vicio de hablar de todo sin otra competencia que la propia voluntad [...]» (Noel, 2007: 26).

${ }^{5}$ Por ejemplo, en su libro de viajes Tierra solares el poeta nicaragüense había afirmado: «El mismo cante flamenco ha degenerado, ha perdido sus bríos antiguos. Vagan aún gloriosas ruinas, como Chacón, famoso por sus "jipíos", tanto como por sus buenas fortunas en aristocráticos caprichos, y Juan Breva, el "cantaor" de Don Alfonso XII, que, viejo corpulento, va hoy por ahí cantando en falsetes lamentables las eternas malagueñas de quejas e hipos, o las amorosas y armoniosas soleares, último aeda del antes triunfante flamenquismo. Dicen de Chacón que es uno de los que han contribuido a la ruina del cante, porque ha sido el decadente con talento de los "cantaores", y los que le han seguido y han querido hacer como él, han resultado con el fracaso de todos los serviles acólitos que sin reflexión ni fuerza imitan. Donde algo queda de las pasadas gracias nativas es en el baile, pues las danzarinas andaluzas guardan aún las mismas condiciones que las hacen aparecer en los exámetros de Juvenal» (Darío, 2005 [1904]: 48-49). Sobre la relación entre Darío y el flamenco puede también consultarse: Álvarez Caballero, 1998, y Rodríguez Baltanás, 1990.

6 Para una aproximación biográfica a Reyles, ver Lerena, 1943. Con este propósito también puede consultarse, Álvarez Márquez, 2012. Por su parte, en Zum Felde (1941: 343-373) se encuentra un recorrido por su producción, donde se incluyen otras ocho novelas como La raza de Caín (1900), El terruño (1916) o El gaucho florido (1932).

7 Como recordaba Zum Felde (1941: 368), anteriormente, en 1902, Reyles había publicado un cuento, titulado "Capricho de Goya", que sintetizaba «los esenciales elementos líricos y dramáticos que la novela ha de desarrollar más tarde», pero que no sucedía en Sevilla, sino en Madrid.

${ }^{8}$ En el caso de El embrujo de Sevilla, Lerena indicaba: «Enjundiosos trabajos se escriben sobre el libro; la prensa internacional lo elogia sin reservas; su fama llega a todos los ámbitos de América, de España y de Francia; se le traduce al inglés, al francés, al alemán y al holandés; las plumas más aceradas le rinden justicia y su nombre está al fin laureado de gloria» (Lerena, 1943: 123). Por su parte, Santa «[...] pronto alcanza un notable éxito en México, que perdurará después de la muerte de su autor» (Ordiz, 2002: 17). De ella se hacen distintas versiones en la pequeña y la gran pantalla. Precisamente, fue un español (Antonio Moreno) el encargado de dirigir una de esas adaptaciones filmicas. Estrenada en 1932 y con un reparto encabezado por Lupita Tovar, fue además la primera película sonora mexicana. En 2015 la directora Mar Díaz dedicó un documental a Moreno (The Spanish Dancer).

${ }^{9}$ Para una semblanza de la vida y obra de Federico Gamboa -autor de otras narraciones como Suprema ley (1896), Metamorfosis (1899), Reconquista (1908) o El evangelista (1922)-, ver Ordiz, 2002: 11-34. Este mismo crítico ofrece una síntesis de Santa: «La novela refiere la historia de una muchacha de un pueblo cercano a la capital, Chimalistac, que, tras resultar engañada por un alférez que la abandona embarazada y
} 
estará ligado a Andalucía y, además, al flamenco ${ }^{10}$ y a lo gitano. Se trata del torero el Jarameño, de quien Ordiz ha afirmado:

Entre ellos [los personajes secundarios], el que tiene mayor presencia en el relato es el torero Jarameño, en cuyas apariciones el narrador emplea todos los tópicos imaginables para un hombre de su oficio. Es también un personaje netamente positivo, que llega a sentir amor verdadero por Santa, a quien retira incluso temporalmente de la profesión y lleva a vivir con él a la pensión de La Guipuzcoana. El torero dispensa siempre un trato exquisito a la joven y, al igual que Hipólito, la ayuda en todo momento, incluso después que ésta le pague sus atenciones con el engaño.

(Ordiz, 2002: 45)

Esta caracterización como personaje positivo lo aleja parcialmente de algunos de los rasgos estereotípicos que desde el Romanticismo se habían venido atribuyendo a la masculinidad gitano-española ${ }^{11}$ :

Hombres cercanos al estado de la naturaleza, con todo lo que ello implica. Desde esta clave deben leerse también los comentarios sobre la condición valiente, estoica, resistente, de los gitanos. [...] La desviación de la norma para ellos no se establece por lo tanto vía emasculación, sino todo lo contrario: estos salvajes son "demasiado" hombres, en tanto que la valentía y el arrojo naturalmente viriles que poseen no están controlados ni bien dirigidos, resultando en consecuencia ineficaces e incluso peligrosos socialmente.

(Sierra, 2019: 59)

El arrojo presupuesto a su condición de torero será una de sus señas de identidad; $\mathrm{y}$, al enterarse de la traición amorosa de Santa, echará mano a una navaja para intentar lavar su honra con sangre -algo que sólo impide la fortuna y la religiosidad del torero, quien acaba aplacándose-. Sin embargo, las atenciones que presta a Santa lo señalarán como un personaje caballeroso y generoso. De hecho, desde su primera introducción en

abortar fortuitamente, es expulsada de su casa y se dirige a la gran ciudad para ejercer la prostitución. Allí Santa se convierte en la reina de la noche capitalina y vive un tiempo amancebada primero con el torero español Jarameño y más tarde con el rico burgués Rubio, mientras el ciego y físicamente detestable Hipólito, pianista del burdel donde la joven presta sus servicios, siente un callado y profundo amor por ella. Un cáncer termina finalmente con la vida de la muchacha tras una operación desesperada y después de un continuo proceso de degradación que la conduce por los tugurios más sórdidos de la ciudad. En sus últimos días Santa vive sin embargo una auténtica historia de amor platónico con Hipólito que, junto con su sufrimiento, parece purificar en este tramo final de su vida al personaje [...]» (Ordiz, 2002: 35-36).

${ }^{10} \mathrm{El}$ estrecho y temprano contacto mantenido entre el arte flamenco y los escenarios mexicanos, y el enriquecimiento mutuo de las sonoridades de ambas orilladas ha sido estudiado, entre otros, por Reyes y Hernández, quienes resaltan «la importante presencia de piezas mexicanas [...] durante el siglo XIX en Andalucía y sobre todo en la ciudad de Cádiz [...]» y «[...] la presencia de las variantes gaditanas en los teatros mexicanos llevadas por las compañías escénicas españolas [...]» (2011: 42). Este interés por el flamenco en el país norteamericano se mantuvo y desarrolló ya bien entrado el siglo XX, como atestiguan, resaltando el caso de la danza, las investigaciones de Santiago (2006) y de Heras (2014).

${ }^{11}$ En cambio, en El embrujo de Sevilla el gitano Pitoche se configura de acuerdo a otros parámetros que encajan con una imagen mucho más negativa del hombre gitano. En este sentido, Sierra apunta: «Su sexualidad y su instinto violento harían imposible la existencia de un orden familiar-sentimental civilizado, y desde esta suposición se le representó frecuentemente como la antítesis del "buen marido", la figura nuclear del orden privado (y, por ende, público) burgués» (2019: 61). Confróntese esta aseveración con esta descripción del Pitoche: «Su especialísima idiosincrasia de gitano le permitía ser, sin esfuerzo alguno, insensible y descastado en materia de amores, y derrochar sentimiento y pasión en su cante [...]» (Reyles, 2002: 84). El Pitoche experimentará un amor enfermizo y violento por Pura, a la que parece estar unido por la terrible sentencia «las gitanas de los gitanos son», que se repite en la novela y que sugiere la justificación, de un modo determinista, del apuñalamiento que Pura comete contra su actual pareja, el señorito/torero Paco Quiñones, para salvar al Pitoche. 
la novela, al llegar al prostíbulo ${ }^{12}$ de Elvira, queda marcado positivamente ${ }^{13}$ por una respetada condición social y por su liberalidad, además de por su asociación con el flamenco:

En primer lugar, lo llevaron a la casa los señoritos de más viso; en segundo, él trató los pesos duros a modo de granos de anís y a las muchachas todas a modo de pesos duros; gastó al igual de sus encopetados amigos, propinó sirvientes, gratificó al pianista, y cuando se adueñó de la guitarra, entonces sí que la victoria se consumó y que las mozas, españolas en su mayoría, batieron palmas y lo premiaron con besos [...].

(Gamboa, 2002: 136)

$\mathrm{Su}$ identificación como andaluz se construirá desde distintos planos: su presentación como gitano ${ }^{14}$, su caracterización lingüística (fonética y léxica) ${ }^{15}$, su noción de patria ${ }^{16} \mathrm{y}$, además, su unión con el flamenco. Con respecto a este último aspecto, en Santa el flamenco aparecerá en distintas ocasiones, pero siempre estará ligado al Jarameño y a su cuadrilla como intérpretes, y a la fiesta nocturna prostibularia o tabernaria como hábitat. Recordemos que esta asociación entre flamenco y ambientes canallas y lumpen era una de las piedras de toque que usaban los intelectuales antiflamenquistas de comienzos del XX para denigrar este arte. Valga como muestra este pasaje del primer cuadro de la más representativa de las comedias flamencas: La copla andaluza, de

12 Para un análisis del burdel como un espacio heterotópico en Santa, ver Shade, 2009.

${ }^{13}$ De esta manera, según Martínez Suárez, el Jarameño formaría parte de la serie de personajes masculinos cuya aparición e interacción con Santa van pautando el devenir de la trama novelística. Este autor explica: «En la narrativa del realismo existe casi siempre una "escena modelo" donde un personaje femenino, en medio de un lugar clausurado, espera con ansiedad —o presiente, o vive — la llegada de un personaje que transformará su visión y experiencia del mundo, y en la mayoría de los casos tal personaje es un hombre [...] espacio, acción y figura masculina, tal es la dinámica permanente en las transformaciones de la anécdota de la novela que aquí destaco y que estructuran en realidad toda la novela, presencia masculina que tendrá signo positivo o negativo según apoye o agreda a la protagonista [...]» (Martínez Suárez, 2012: 442).

${ }^{14}$ Se recurre así a un uso sinecdóquico que equiparará recurrentemente lo español y lo andaluz con cierta noción de lo gitano, y que tenderá a ser reproducido en décadas posteriores a través de otros lenguajes creativos como el cine, por ejemplo, gracias al fenómeno de las coproducciones entre España y, especialmente, México a mediados del XX. Por otro lado, uno de los rasgos que en la novela se presentan como propios de este personaje gitano subraya una conexión con lo desconocido y lo irracional, algo que, al menos desde el Romanticismo, se había convertido en una de las claves del estereotipo gitano-español, sobre todo en el caso femenino. Concretamente, se alude a la condición supersticiosa del torero: «Quieras que no, por más que perseguido de sus supersticiones de gitano tratase de apartar la vista, sobróle tiempo para presenciar el lúgubre cuadro [...]» (Gamboa, 2002: 207); «Es que si se descompasa uno la víspera de torear — será gitanería, concedido—, ¡ay hija!, se corre el riesgo de torear por última vez [...]» (Gamboa, 2002: 235).

${ }^{15}$ Entre otros recursos de caracterización lingüística, se menciona, por ejemplo, su pronunciación ceceante ( ¿Diga usté, salecita del mundo - le preguntó con exagerado cecear andaluz-, usté no tiene cortejo?...», Gamboa, 2002: 136) y se destaca su particular léxico, donde se incluyen términos en caló (gachó, diquelar).

16 Sobre este particular, sentencia: «-Siempre España, ¡mire usted qué cosa! Pero sin islas ni ultramares... y tampoco España entera, que ni conozco. Mi patria es — continuó el Jarameño contando con los dedosmi Andalucía; mi cortijo, la tumba de mis viejos, que de Dios hayan; y la ventana con claveles y geranios que guarda unos ojazos y un corazoncito que yo me sé... ¡Eso sí es mi patria!» (Gamboa, 2002: 145). Esto no impide que reconozca la gentileza con la que México lo ha acogido, gesto que abunda en su pintura como personaje amable. Sirva de ejemplo este pasaje en el que, tras una discusión inicial sobre el Grito de Dolores, el Jarameño cede y decide asistir a la celebración de ese hito histórico: «-Jarameño, iqué te pones tonto!, ¿vas a reñir por vejeces, bárbaro? Son cosas que pasan y sanseacabó. Ya todos somos uno, y ustedes aquí, más, ¿quién te ha maltratado?, ¿no ganas aplausos y dinero?, ¿no miras miles y miles de compatriotas tuyos que ni a tiros se marcharían, de lo contentos que se hallan?... — ¡No, lo que es de ser cierto, sí que lo es... ea!, dispensar y contar conmigo mañana. ¡A ver, patrona, manzanilla, que un español convida a beber por España!» (Gamboa, 2002: 138). 
Antonio Quintero y Pascual Guillén: «Nuestra copla andaluza, esa magnífica explosión de dulzura, de altivez, de dolor y de humorismo que es nuestra copla, se envilece, como la mujer, en cuanto busca cobijo en la taberna» (Quintero \& Guillén, 1929 [1928]: 20).

Esta vinculación también se traduce en una asociación connatural entre estos toreros-flamencos y juerga: «[Al alba] A la carrera disolvía la reunión; avergonzados los unos de los otros, de sí mismos algunos. Sólo las mujerzuelas y los toreros se marchaban tan campantes, connaturalizados con lo que signifique desórdenes y excesos» (Gamboa, 2002: 164). Por ello no resulta extraño que el Jarameño, además de por sus dotes tauromáquicas, sea respetado entre los suyos por sus habilidades y conocimientos musicales ${ }^{17}:$ «[...] cogió de nuevo la guitarra, y entre cañas y palmas "se arrancó por lo hondo" con el melancólico repertorio flamenco: Dos cosas hay en el mundo / que la vida costar pueden ...» (Gamboa, 2002: 137); y, más adelante: «— Eso está en el orden, ¡ajo! ¡Por ti, tú! Eso es cantarse una malagueña...» (Gamboa, 2002: 163).

Gamboa, hasta cierto punto, orientaliza ${ }^{18}$ a esos personajes andaluces. Así, el cante y el baile los alejan de sus compañeros de jarana mexicanos en un proceso de exotización en el que se codifica una idea compartida de masculinidad, caracterizada por la adustez y la melancolía expresada a través de lo musical:

¡Qué difícil hacerlos bailar! Desdeñaban los contoneos de la danza, desdeñaban admiradores y adoradoras; y conforme vaciaban «cañas» del vino de su país, parecía que el tal, de la cabeza sólo la memoria les invadiera sin perturbársela, antes sacando a orear en sus arábigos ojos los melancólicos recuerdos, las ternezas de la tierruca, los amaneceres de los cármenes de Andalucía y los anocheceres junto a la reja de las Cármenes andaluzas. El menos desafinado de la cuadrilla rompía el canto y los demás rompían a jalearlo con los bastones sobre el piso, con las «cañas» sobre el mármol de la mesa, con palmas, olés y palabras cortadas, de estímulo.

(Gamboa, 2002: 162)

En esta ocasión, la irrupción del flamenco provoca que la acción entre en un paréntesis del que los personajes ajenos al espectáculo quedan prácticamente expulsados. La juerga acaba por volverse dramática y la actuación flamenca llega a adquirir tintes sombríos que sólo son vividos con toda su intensidad por los toreros-músicos. El espectáculo flamenco opera como una práctica ritual que funciona como un elemento de cohesión grupal $-\mathrm{y}$, por lo tanto, una marca identitaria - con capacidad catártica:

Todos cantaban, alternados, en una especie de junta sentimental y poética; quién hablando de la madre, quién de la novia, quién de cárceles, casi todos de muerte y cementerios; identificándose con su canto, por él desdeñosos de amigos y enamoradas; a los comienzos, con el pueril deseo de cosechar aplausos, ligeramente teatrales; después, posesionados de nostalgias, cerrando los ojos al brotar de sus gargantas los versos intensos, para mejor verse por dentro de lo que por dentro les bullía y ahogaba.

(Gamboa, 2002: 162-163)

Como se puede apreciar, existen distintas características que marcan la aparición y el uso del flamenco en Santa. Por un lado, Gamboa privilegia una visión melodramática del flamenco, que lo asocia a temáticas trágicas, melancólicas y a la reflexión interna, pero que, paralelamente, posee capacidades terapéuticas. Por otro lado, el cante, el toque

\footnotetext{
${ }^{17}$ Igualmente, en El embrujo de Sevilla el torero Paco Quiñones hará gala de sus habilidades para el cante y el toque flamencos.

18 Para la noción de orientalismo que se tiene en mente en este pasaje, cfr. Said, 2004 [1978]. Allí, Said consideraba que la visión de Oriente creada por los orientalistas es «a discursive production, a fantastic place that is the product of hundreds of years of mystification, exoticization, and outright deception made possible by the discrepant power relations between West and and East» (Buchanan, 2018: 368).
} 
y el baile identifican a los personajes andaluces como una seña de identidad colectiva. Y, por último, su aparición en la trama de la novela da la posibilidad de introducir interludios musicales con los que pintar con mayor viveza el ambiente de fiesta del burdel o la cantina.

\section{HIEROFANTES QUE ZAPATEAN: LA RELIGIÓN FLAMENCA EN EL EMBRUJO DE SEVILLA (1922), DE CARLOS REYLES}

En la introducción a su edición de El embrujo de Sevilla ${ }^{19}$ González Troyano aporta algunas claves valiosas para enmarcar correctamente esta singular novela de Carlos Reyles. Por un lado, reconoce que, cuando el autor uruguayo publica su obra, la materia de Andalucía (como la denominó Enrique Rodríguez Baltanás) se veía asediada intelectualmente -que no comercialmente-:

Durante más de un siglo - desde las décadas románticas, e incluso desde antes-, gitanos, toreros, aristócratas castizos, bailaoras y cantaores, habían proporcionado argumentos, escenificados en Sevilla, para novelas, obras de teatros, artículos costumbristas y libros de poesía. Pero ese mundo, igual que la voz embrujo - que tanto se presta a acompañarlosi bien facilitó grandes logros literarios, padecía ya, por aquellos años, de una cada vez mayor degradación y acartonamiento, a la vez que despertaba recelos en los círculos intelectuales más obsesionados por la modernización de España.

(González Troyano, 2002: s/p)

Pero, por otro lado, sitúa a Reyles como puente que conectará con nuevas sensibilidades literarias en el tratamiento de lo andaluz, lo cual lo coloca en una sintomática posición de renovador de esta tradición literaria en un momento en el que sobre ésta pendía la extensión metonímica del calificativo de quincalla meridional orteguiano ${ }^{20}: \ll[\ldots]$ coincide con ellos [la generación del 27] en haberse desprendido de los anteriores prejuicios regeneracionistas y elevar el escenario de la fiesta de toros y del cante jondo - y sus intérpretes - a la misma dignidad literaria de cualquier otro» (González Troyano, 2002: s/p).

Uno de los rasgos que, según González Troyano, caracterizan la propuesta de Reyles es incluir «la reflexión apologética dentro de la propia intriga narrativa. Y, así, los personajes no sólo mostrarán sus vidas, también querrán exponer el ideario justificativo de las mismas» (González Troyano, 2002: s/p). Como revisaremos a continuación este hecho hace que la novela incorpore abundantes menciones al flamenco y, no sólo eso,

\footnotetext{
19 La línea argumental de la novela la resumía ya Torres-Rioseco (1939: 340): «Los personajes más importantes de El embrujo de Sevilla, son Paco Quiñones, matador de alta alcurnia social, y la Pura, bailaora famosa [...]. El escenario es El Tronio, café de canto y baile flamencos. Allí se encuentran el héroe y la heroína de Sevilla. Y como es 1ógico, se aman. Y este amor hace revivir la pasión del cantaor Pitoche por la Pura. Pitoche trata de reconquistar a su antigua amante, pero ella le rechaza indignada. En cierta ocasión Pitoche agrede navaja en mano a Paco, pero éste lo desarma y va a estrangularlo cuando el cantaor implora la ayuda de Pura. El viejo amor de la chula por el golfo que la había perdido estalla en el pecho de la mujer como un incendio voraz, según el autor, y la Pura recoge la navaja y hiere a Paco en la espalda. La mujer se va con el Pitoche y Paco queda moribundo. Al otro día la Pura se da cuenta de su tremenda culpa y corre a informarse del estado de su amante. Paco mejora después de algunos meses, gracias a los cuidados de su novia, Pastora, con la cual se casa más tarde. La Pura decide irse de Sevilla a purgar eternamente su pecado».

${ }^{20}$ Reproduzco el fragmento aludido de Ortega, extraído de "Teoría de Andalucía": "Claro es que este retorno a lo andaluz — si aconteciera - implicará una visión de Andalucía completamente distinta de la que tuvieron nuestros padres y abuelos. No hay probabilidad de que nos vuelva a conmover el cante hondo, ni el contrabandista, ni la presunta alegría del andaluz. Toda esta quincalla meridional nos enoja y fastidia» (Zambrano \& Ortega y Gasset, 1984: 232).
} 
sino toda una serie de reflexiones de mucha mayor transcendencia que tendrán a este arte como centro de atención.

En este sentido, Reyles se nos presenta como un buen conocedor del flamenco del momento y esto lo deja patente a través de diversos recursos. Introduce el trasunto de un artista real como personaje de la trama. Es el caso de Silverio -alusión a Silverio Franconetti ${ }^{21}$, que aparece como el dueño del café cantante El Tronío ${ }^{22}$. Asimismo, inserta alusiones a reconocidos cantaores (Breva, el Canario, Chacón, el Loco Mateo, la Andonda, la Peñaranda, la Serneta, etc.) o bailaoras: «-Esa niña va a revolucionar el baile. La vi en Córdoba, ¡un escándalo! Lo que hacen la Mejorana, la Macarrona y tantas otras son juegos de niños junto a lo suyo» (Reyles, 2002: 30). No obstante, particularmente interesantes resultan las reflexiones que sobre el propio arte flamenco lleva a cabo Reyles en relación con su tesis sobre la configuración de la esencia del espíritu de Sevilla y Andalucía. Éstas nos muestran una suerte de Reyles flamencólogo, que es capaz de incidir en algunos de los asuntos que afectaban a las discusiones sobre el flamenco del momento a través de su obra creativa.

Así pues, obsérvese cómo en un mismo pasaje los personajes enfrentan problemas como el de la consideración musicológica del flamenco ( «-Y todavía hay quienes niegan al cante todo, hasta que sea música, porque no está sujeto a ciertos cánones, porque es pura libertad y expresión directa. Que Dios me perdone si digo una herejía, pero a mí, ninguna música, fuera de la música de Beethoven, me remueve las entrañas como ese lloro de gitanos, porque ninguna es tan pueblo, tan miserable, tan humana...», Reyles, 2002: 31); o, implícitamente, se presenta la división entre cante grande y cante chico ${ }^{23}$ : «-A mí se me figura más bien que lo hondo, lo gitano, viene de adentro, de abajo -

${ }^{21}$ Precisamente, será a través de Franconetti a partir de quien se pueda trazar una de las vinculaciones más interesantes entre flamenco y el país de origen de Reyles. La experiencia del genial cantaor en Uruguay (1857-1864) fue estudiada por Steingress, quien, si bien documentaba su labor como picador en 1857, reconocía que no se habían podido localizar testimonios de su actividad flamenca, a pesar de la presencia del género andaluz en los escenarios del Cono Sur a mediados del XIX: «Los aficionados del baile y el canto andaluz en el Río de la Plata conocieron la cachucha, el jaleo de Jerez, el zapateado y otros bailes del género pre-flamenco, pero no a Silverio» (2006: 187). Eso sí, considerando la existencia de otros tipos de establecimientos (tabernas, cafés, pulperías, candombes) y la importancia de la música y el baile en el Uruguay de la época, Steingress suponía: «[...] pese a la falta de documentación, que Silverio cantó entre sus compañeros y en el entorno social de toreros, matarifes y el submundo que lo rodea» (2006: 188).

22 Si en Santa el flamenco encontraba un espacio privilegiado de desenvolvimiento en el prostíbulo de Elvira o en el restaurante y cantina Tívoli Central («por mil títulos afamado establecimiento nocturno y pecador», Gamboa, 2002: 151), en El embrujo de Sevilla tendrá lugar prioritariamente en el café cantante El Tronío. Al inicio de la novela, Reyles ofrece una detallada descripción del mismo; allí apunta: «El Tronío es, no sólo la Meca del cante, toque y bailes flamencos, donde se conservan las viejas tradiciones de ese extraño arte o acrisolan sus nuevas modalidades, sino también una especie de lonja en la que se cotizan los méritos de la gente de coleta y los artistas del tablao [...]» (Reyles, 2002: 9). Igualmente, encontramos pronto la alusión al tablao como círculo mágico («Los ojos se clavaron en el círculo mágico donde el corazón del pueblo andaluz sufría el embrujo de las malagueñas y los tangos, las soleares y las seguiriyas», Reyles, 2002: 27-28).

Para un recuento histórico del devenir de los primeros cafés cantantes sevillanos, vinculados estrechamente con el de la novela y la figura de Silverio Franconetti, ver Blas Vega, 1987, y Gamboa, 2011: 306-307. Para una descripción de estos locales y de los elencos artísticos que actuaban en ellos, ver Navarro \& Pablo, 2005: 55-56.

23 Esta división taxonómica está presente en tempranas obras de los estudios flamencos, así, cuatro años tras la publicación de la novela de Reyles, José Carlos de Luna dio a conocer De cante grande y cante chico (1926). Más adelante, González Climent se referiría a ella en estos términos: «La situación-límite es el suscitadero temático del cante grande: la muerte, el sino, el acaso, la culpa, etc. [...] Representa un enfrentamiento pasional con lo absoluto», y continuaba: «[...] arte y anécdota en las situaciones-comunes del "cante chico"; tragedia y verdad en las situaciones-límites del "cante grande". Con más brevedad: el “cante grande” es metafísica; el "cante chico”, psicología y estética» (González Climent, 1989: 94 y 95). 
replicó Cuenca - La seguiriya es como el tiburón, que sube a pique del fondo del mar a la superficie, coge su presa y se vuelve a las profundidades» (Reyles, 2002: 31), y, más adelante en esa misma página: «A los tangos y a las alegrías, a lo que se llaman juguetes, les pone ella una salsa de pasión, una furia gitana que los trueca, como si dijéramos, en baile hondo». Asimismo, Pura aparece como una creadora que renueva el baile flamenco $\mathrm{y}$, si al comenzar la novela sostiene: «Quiero hacer de cada baile un cuadro, lo que llaman por allá un balé, y de cada cante una interpretación coreográfica con su decorado propio y música típica» (Reyles, 2002: 60), en las páginas finales conocemos sus planes de futuro: «Allí [teatro Olympia de París] se proponía estrenar los bailes de su invención: la Seguiriya, la Saeta, la Malagueña, la Soleá [...]» (Reyles, 2002: 278).

Especialmente significativa resultará la inclusión del flamenco como parte axial de la configuración de la idea de Andalucía y España que sostiene el autor uruguayo. Más adelante, Reyles expondrá, de forma ensayística, en «Resonancias de Sevilla. Los órganos estéticos de la ciudad bruja» ${ }^{24}$ su visión de la identidad andaluza, que considera transida por lo trascendental encarnado en una serie de prácticas concretas: el cante y el baile flamencos, el toreo, y la devoción religiosa popular:

[...] sólo lo popular revela el problema y el enigma que cada andaluz lleva dentro de sí y es algo así como su yo. [...] Así el toreo y su ambiente, el cante jondo y su atmósfera, el baile flamenco y su paisaje, la devoción y su dardo místico, la saeta, símbolo del sentimiento religioso, son manifestaciones máximas aunque recónditas y humildes, de un estilo de vida personalísima, los cuatro puntos cardinales de la sensibilidad autóctona de un pueblo.

(Reyles, 1965: 163)

Reyles se opone fervientemente a la denostación antiflamenca propia de una buena parte de la generación del 98 y se erige en valedor de la fuerza vital ${ }^{25}$ que subyacería tanto en el artista flamenco como en el torero, y los toma como los más valiosos e inspiradores símbolos de lo andaluz. En la novela leemos: «Sin duda, el torero célebre es, aunque parezca paradoja o enorme dislate, el profesor de energía e idealismo de nuestras multitudes» (Reyles, 2002: 34). Y Zum Felde remacha: «Esas ideas [las del pintor Cuenca, por cuya boca diserta el autor] - de acuerdo con el realismo antiracionalista profesado por Reyles [...] significan una defensa de la España bárbara contra las pretensiones europeizantes de los progresistas, siendo su punto capital la apología de la tauromaquia» (Zum Felde, 1941: 369-370). ${ }^{26}$

Va de suyo que la pareja protagónica (la bailaora Pura la Trianera y el torero Paco Quiñones) opera como símbolos hipostasiados de la idea-en el sentido platónico-que de Andalucía propone Reyles. De hecho, la equiparación entre Pura y Andalucía/Sevilla se hará de forma explícita en varios momentos de la novela (Reyles, 2002: 40, 46, 59), y de Paco, vestido de torero, se dirá: «Aquel mozo era la encarnación viviente y la cifra de la

\footnotetext{
24 Sobre este texto, Aínsa explica: «Esta intensa relación [entre Reyles y Sevilla] culmina al ser designado Presidente de la Comisión uruguaya en la Exposición Iberoamericana de 1929. Su intervención el día 18 de octubre en que se celebra el día del Uruguay, "Resonancias de Sevilla", es clave para comprender lo que llama "los órganos estéticos de la ciudad bruja". El texto ampliado lo recoge en Incitaciones (1930)» (Aínsa, 2012: 456).

25 Por su parte, Visca recuerda la importancia del concepto ilusiones vitales para entender la configuración y la trascendencia de los protagonistas: «Las ilusiones vitales se confunden ahí con la realidad misma, porque no son juegos imaginativos ni construcciones mentales, sino desborde pasional nacido de una vivencia dionisíaca de la vida. Son, en rigor, manifestaciones de una energía que viene de lo más hondo de la vida y se desborda en el ruedo o en el tablao» (Visca, 1992: 109).

26 Zum Felde reconocía en Cuenca la impronta de otros pintores como Ignacio Zuloaga y Julio Romero de Torres (1941: 369).
} 
gracia y del machismo andaluz; un símbolo de lo más hondo y enjundioso del alma sevillana [...]» (Reyles, 2002: 129). Lerena lo expresó con estas palabras: «Las figuras son símbolos, unidos entre sí por emociones galvánicas, moviéndose en una ciudad de ensueño y de poesía, riente, dolorosa y mística» (Lerena, 1943: 124).

La conceptualización del flamenco como práctica trascendental queda aún más patente al observar cómo Reyles alude continuamente a este hecho con un vocabulario y una serie de paralelismos de raíz religiosa en la novela, pero también en el ensayo: «El tablao es la capilla ardiente del arte popular y su creación no remonta muy atrás. Antaño éste no tenía templo ni sacerdotes tonsurados, pero sí elegidos» (Reyles, 1965: 167); «[...] el cante jondo se escucha religiosamente» (Reyles, 1965: 173); «Y yo te digo: mi cantaor es el hierofante de una religión misteriosa y, por añadidura, un soberano artista» (Reyles, 1965: 180). Estamos ante una religión de pasión que vive en el ideal de una España heroica y se celebra a través de rituales musicales.

La bailaora, por su parte, oscila entre bacante y pitonisa (Reyles, 1965: 178-179), y junto con el cantaor oficiarían como dignatarios de esa religión flamenca que tendría como principal espacio sacro el tablao, donde el arte llegaría a las más altas cotas de refinamiento («El cante jondo, antes de fijarse, aún cerril, tenía ya perfil propio, fisonomía inconfundible, estilo y tradición. El tablao lo recoge del arroyo, refina, acrisola y convierte en organismo musical, lo que lo diferencia y eleva sobre la mera canción», Reyles, 1965: 167).

De un modo similar a lo analizado en Santa, dentro de esta lógica de lo trascendental, la actuación flamenca adquiere los tintes de rito y sacrificio, de expurgación catártica. Así Reyles pone en boca de Silverio lo siguiente: «-Templarme y ponerme a sufrir era todo uno -decía-, y eso les pasa a todos los güenos cantaores. El cantaor sin sufrimiento es una guitarra sin cordaje: hace ruido, pero no suena» (Reyles, 2002: 38). Esta visión patética y catártica del flamenco conquista una de sus cimas en el pasaje en el que el Pitoche se coloca frente al paso de la Virgen de la Esperanza para cantarle una saeta que concluye con un «Perdona a los que han llorado»: «En su transporte no sabía si le cantaba a la Virgen o a la Pura; si el crucificado era él mismo o el Redentor; confundía los tormentos del Hijo y de la Madre con los tormentos de la bailadora y los suyos propios [...]» (Reyles, 2002: 295). Más allá de confesionarios al uso, es a través de su interpretación de la saeta como el Pitoche solicita ser redimido. La actuación flamenca queda validada así no sólo como un medio altamente adecuado para la expresión del dolor y la contrición, sino también como un mecanismo performativamente útil para propiciar la catarsis.

\section{CONCLUSIONES}

La simpatía con la que Gamboa dibuja al Jarameño - aunque esto no sea una opinión unánime ${ }^{27}$ - y no digamos el panegírico que Reyles hace de su visión de Sevilla

27 Gier ha considerado que, más allá del personaje del Jarameño, pero incluyéndolo, los personajes españoles que aparecen en la novela son juzgados severamente: «No obstante, si nos damos cuenta de que el Jarameño, el único español que socorrió a Santa, regresa a la Península, cabe pensar que a través de este irónico acontecimiento se expresa un deseo latente en México (o en Gamboa) de que España dejara de ejercer su influencia en el país. En Santa se permite entrever con claridad el deseo de un segmento de la sociedad mexicana, del cual el mismo Federico Gamboa es un representante, de que México resurgiera libre del yugo de la influencia peninsular. En lugar de examinar el impacto de Porfirio Díaz y el gobierno en la moral de la sociedad mexicana, Gamboa centró su novela en los españoles como fuente de la ruina de la vida de Santa, y por ende, de la de México también» (Gier, 1998: 142). Ordiz, en cambio, da prioridad en cuanto al blanco de las críticas de Gamboa a otro colectivo: «Desde sus convicciones católicas, Gamboa no podía estar de acuerdo con el laicismo y el cientificismo de los teóricos del régimen [porfirista]. En línea 
encajan con una atracción por España como referente cultural frente al mundo anglosajón ${ }^{28}$. No obstante, en el caso de Gamboa no todos los personajes españoles están representados con tanta amabilidad como el Jarameño, e incluso este mismo también es objeto de alguna burla por parte del autor a costa de su ignorancia de la historia mexicana en los pasajes referentes a la celebración del Grito de Dolores, y a costa de su atrabiliario patriotismo. Esto casa con las siguientes palabras que Gamboa dejó escritas en su diario: Tengo por principales características del español [...] antes que nada, un morboso orgullo individual; luego, un increíble desprecio a la muerte, clave de su valor sobradamente acreditado; una crueldad nata, sanguinaria e incurable que lo empuja a los peores excesos; patriotismo hiperestesiado, aunque defectuoso, pues la mayoría de las provincias, por causas históricas y raciales, ponen por encima de la patria grande a la patria chica (Gamboa 1995-V: 220).

(Apud Prendes, 2009: 234)

En cuanto a Reyles, combina una visión de los andaluces que se aviene a los presupuestos manejados por intelectuales coetáneos y que los atan a un inmovilismo hedonista, pero ofrece una posible salida para las aspiraciones creativas personales ${ }^{29}$. En el primer caso, cotéjense estas palabras de Paco: «Nuestra despreocupación es nuestra miseria y nuestro tesoro. No tenemos voluntad, pero la tiene por nosotros Nuestro Padre Jesús del Gran Poder. Dios no nos da la ciencia, pero nos da la gracia; no sabemos trabajar, pero sabemos divertirnos» (Reyles, 2002: 63); con estas otras de Ortega y Gasset: «Podrá en el andaluz ser la pereza también un defecto y un vicio; pero, antes que vicio y defecto, es nada menos que su ideal de existencia» (Zambrano \& Ortega y Gasset, 1984: 240). En otro ejemplo, Paco comenta:

Había visto las Exposiciones Agrícolas de Inglaterra y Francia, y conocía las excelencias de los ganados y cultivos de los dos países, pero, por amor a la tradición y natural desidia, jamás se le ocurrió, como no se le había ocurrido antes a su tío, que se podría cambiar el arado de madera por el de hierro, ni las ovejas churras por las lincoln de gran desarrollo y espléndido vellón.

(Reyles, 2002: 62-63)

con otros pensadores del ala conservadora, el escritor achacará al olvido de los principios religiosos la degradación que se vive en el país cuyos habitantes, formados en un sistema educativo que excluye toda moral, dan rienda suelta a su egoísmo y a sus más bajos instintos. Esta situación afecta sobre todo a la capital $[\ldots] \gg($ Ordiz, 2002: 24).

28 Para Gamboa, Ordiz señala: «[...] la comunidad de pensamiento entre ambos escritores [Gamboa y Rodó] se expresa no sólo en su mutuo rechazo del mundo utilitario anglosajón, sino también en su visión de España ya no como el enemigo de antaño sino como el origen de un importantísimo legado cultural que debía preservarse frente a las amenazas foráneas» (Ordiz, 2002: 27). Por su parte, Aínsa apunta sobre Reyles: «En sus Diálogos Olímpicos (1918) sitúa a la Ilusión Vital en España — como había hecho en "La flor latina", tercer ensayo de La muerte del cisne (1910) — única nación que encarna la esperanza de la continuidad del latinismo. Gracias a su casticismo puede sostener los ideales latinos frente a los anglosajones y germanos que amenazan adueñarse del mundo» (Aínsa, 2012: 457).

${ }^{29}$ De Mora sintetiza la tensión existente entre estas dos posiciones al comentar: «En consecuencia, el sentir de Reyles parece inclinarse hacia la conjunción de ambas visiones opuestas: progreso, sí, pero sin renunciar a esos valores tan propios del andaluz que le predisponen de modo especial para el goce de vivir, para saber rodearse de belleza y alegría, precioso legado de sus antecesores árabes tan dados a la voluptuosidad y el refinamiento» (De Mora, 1981: 372-373). No obstante, también añade: «El error de Reyles en su visión de Andalucía y, por proyección, de España nace en el instante mismo en que propone una especie de regresión hacia el pasado para recuperar las energías perdidas sin detenerse a examinar las causas de nuestro fracaso como hiciera Frank [España Virgen]. Tampoco proyecta su mirada hacia el futuro ni propone paliativos para no quedarnos descolgados del resto de Europa» (De Mora, 1981: 375). 
Estas palabras recuerdan mucho a una de las andanadas que Eugenio Noel lanzaba contra los señoritos chulos en 1916:

En cierta estación etnológica se da una conferencia sobre la pasteurización de los vinos. No es posible tema más práctico, más interesante para una comarca vinícola que produce mostos fuertes. Se acude a la conferencia, porque el ingeniero está casado con la prima de una tía segunda del hermano del cacique, y no acudir es peligroso. Se oye. Se sale. Y en la calle se escucha algo parecido a esto: - Vaya una lata. - Pues parece que tiene razón. - Y tanta como tiene; pero todo eso es una lata.

(Noel, 2014: 19)

El flamenco y el toreo serían entonces espacios privilegiados de acción vital para los andaluces y medios idóneos de expresión de esa voluntad de creación individual que Pura identifica como chalaura y Paco -en principio- como guilladura. Pura conseguirá sacar de su pasividad hedonista a Paco: «Sin ella no se me hubiera ocurrido pensar lo que pienso ni hacer lo que hago delante de los toros. Ella me abrió la apetencia de la gloria y enseñó a torear mostrando el alma de la raza» (Reyles, 2002: 301). Pasión creadora flamenca y fervor tauromáquico se proponen, pues, como señas de una renovada identidad española, retroalimentándose en una simbiosis fecunda, de ahí que Paco le confiese a Pura: «[...] se me antoja que tú sola me comprendes y quieres como hace falta quererme y comprenderme» (Reyles, 2002: 167).

En fin, Gamboa y Reyles recurren, entre otros elementos, al flamenco como hecho diferencial que caracteriza culturalmente a lo andaluz, y con ello construyen, sobre todo en el segundo caso, una visión de la identidad de esta zona de España, llegando a conclusiones concurrentes en cuanto al flamenco como una práctica musical transcendental. De este modo, se nutrieron de y contribuyeron a la cadena (o espiral o rizoma) semiótica de la materia de Andalucía, y pudieron aprovechar los dividendos simbólicos - y materiales - que ello proporcionaba, pero también, y sobre todo en el caso de Reyles, han tenido que afrontar las revisiones críticas que sobre este particular imaginario se han ido desarrollando, algo ocurrido no sólo a posteriori, sino desde prácticamente los momentos iniciales del fervor literario por lo andaluz ${ }^{30}$.

\section{AGRADECIMIENTOS}

Quisiera agradecer a Mar Díaz las facilidades concedidas para poder visualizar el documental The Spanish Dancer. Igualmente, desearía reconocer la labor de mis compañeros de la Biblioteca Americanista de Sevilla, CSIC, quienes han posibilitado el acceso a distintas referencias bibliográficas. Por último, estoy en deuda con mi colega Francisco J. Escobar Borrego por animarme a escribir la primera versión de este artículo. Su cabalidad intelectual y flamenca es un estímulo permanente.

\footnotetext{
${ }^{30}$ González Troyano recuerda, entre otros, los casos de Estébanez Calderón y Fernán Caballero, quienes pretendieron corregir las visiones inexactas de Andalucía que, según ellos y otros narradores costumbristas, habrían producido diversos autores extranjeros y cómo: «Este mecanismo se convirtió en un recurso tan tipificado que es raro encontrar un artículo costumbrista, de la década de los treinta y cuarenta, del siglo XIX, que no comience adelantando la intención de realizar un retrato "auténtico" que corrija los desmanes que otros escritores extranjeros habían diseminado. Y este juego de intenciones resulta tanto más paradójico cuanto que en la mayoría de estas escenas andaluzas va a prodigarse el mismo enfoque tantas veces criticado» (González Troyano, 2018: 20).
} 


\section{REFERENCIAS BIBLIOGRÁFICAS}

Aínsa, Fernando. 2012. «Carlos Reyles. Del decadentismo parisino al embrujo de Sevilla». En Viajeros, diplomáticos y exiliados. Escritores hispanoamericanos en España (1914-1939), vol. II, eds. Carmen de Mora y Alfonso García Morales, 451-463. Bruxelles: P.I.E. Peter Lang.

Álvarez Caballero, Ángel. 1998. «Flamenquismo y antiflamenquismo en la Generación del 98». En La Generación del 98 y Manuel Machado ante el Flamenco, ed. Ángel Álvarez Caballero. La Unión: Ayuntamiento de La Unión, pp. 29-48.

Álvarez Márquez, Juan. 2012. «Carlos Reyles y los lazos culturales hispano-uruguayos». En Viajeros, diplomáticos y exiliados. Escritores hispanoamericanos en España (1914-1939), vol. II, ed. Carmen de Mora y Alfonso García Morales. Bruxelles: P.I.E. Peter Lang, pp. 465-478.

Berlanga, Miguel Ángel. 2015. «The fandangos of Southern Spain in the context of other Spanish and American fandangos». Música oral del Sur, 12: 171-184.

Blas Vega, José. 1987. Los cafés cantantes de Sevilla. Madrid: Cinterco.

Buchanan, Ian. 2018. A Dictionary of Critical Theory. Oxford: Oxford University Press.

Castro Buendía, Guillermo. 2014. «Música e historia del zapateado». Revista del Centro de Investigación Flamenco Telethusa, 7.8: 22-37.

Cruces, Cristina (ed.). 1998. La bibliografia flamenca, a debate. Sevilla: Centro Andaluz de Flamenco.

Darío, Rubén. 2005 [1904]. Tierras solares. Alicante: Biblioteca Virtual Miguel de Cervantes [edición digital basada en la de Madrid: Leonardo Williams]. http://www.cervantesvirtual.com/obra/tierras-solares--0/

De Mora Valcárcel, Carmen. 1981. «Visión de Andalucía en la obra de Reyles». En Actas de las Primeras Jornadas de Andalucía y América, La Rábida, vol. 2, prólogo de Bibiano Torres Ramírez. Huelva: Instituto de Estudios Onubenses (Diputación de Huelva), pp. 365-378. https://idus.us.es/handle/11441/18028

Gamboa, Federico. 2002. Santa. Madrid: Cátedra.

Gamboa, José Manuel. 2011. Una historia del flamenco. Barcelona: Espasa.

—. 2016. ¡En er mundo!: de cómo Nueva York le mangó a París la idea moderna del flamenco. Flamenconautas. $1^{a}$ parte: pioneros y conquistadoras. Sevilla: Athenaica.

—. 2017. ¡En er mundo!: de cómo Nueva York le mangó a París la idea moderna del flamenco. Flamenconautas. $2^{a}$ parte: el crack de la bolsa y los cracks de flamenco. Sevilla: Athenaica.

Gier, Daniel. 1998. «El elemento español en Santa, de Federico Gamboa». Revista Canadiense de Estudios Hispánicos, XXIII.1: 132-143.

González Climent, Anselmo. 1989. Flamencología. Córdoba: Ediciones de La Posada, Ayuntamiento de Córdoba.

González Troyano, Alberto. 2002. «Introducción». En El embrujo de Sevilla, Carlos Reyles, s/p. Sevilla: Ayuntamiento de Sevilla.

- 2018. La cara oscura de la imagen de Andalucía. Estereotipos y prejuicios. Sevilla: Centro de Estudios Andaluces.

Heras Monastero, Bárbara de las. 2014. «Primeros profesionales de la danza española y flamenco en la Ciudad de México entre 1920-1950». Música oral del Sur, 11: $141-166$.

Lerena Avecedo de Blixen, Josefina. 1943. Reyles. Montevideo: Impresora L.I.G.U.

Martínez Suárez, José Luis. 2012. «Santa: una lectura social. Representación literaria de aspectos culturales del Porfiriato». En Todos somos iguales frente a las 
tentaciones. Una antología general, Federico Gamboa, selección, estudio preliminar y cronología Adriana Sandoval. Ciudad de México: Fondo de Cultura Económica, Fundación para las Letras Mexicanas, Universidad Nacional Autónoma de México, pp. 435-448.

Navarro García, José Luis y Eulalia Pablo Lozano. 2005. El baile flamenco. Córdoba: Almuzara.

Noel, Eugenio. 2007. República y flamenquismo. Mairena del Aljarafe: Extramuros.

—. 2014. Señoritos chulos, fenómenos, gitanos y flamencos. Córdoba: Berenice.

Ordiz, Javier. 2002. «Introducción». En Santa, Federico Gamboa. Madrid: Cátedra, pp. 9-60.

Ortiz Nuevo, José Luis. 2019. Tremendo asombro. Huellas del género andaluz en los teatros de La Habana y otras informaciones a lo flamenco (1790-850). Sevilla: Athenaica.

Prendes Guardiola, Manuel. 2009. «Federico Gamboa: Un escritor mexicano en Europa». Anales de Literatura Hispanoamericana, 38: 223-235. https://revistas.ucm.es/index.php/ALHI/article/view/ALHI0909110223A/21538

Quintero, Antonio y Pascual Guillén. 1929. La copla andaluza. Madrid: Prensa Moderna. Reyes Zúñiga, Lénica y José Miguel Hernández Jaramillo. 2011. "Cádiz como eje vertebrador en España del discurso dialógico musical entre México y Andalucía en la etapa preflamenca». Revista del Centro de Investigación Flamenco Telethusa, 4. 4: $32-43$.

Reyles, Carlos. 1965. Ensayos, tomo III. Montevideo: Ministerio de Instrucción Pública y Previsión Social.

—. 2002. El embrujo de Sevilla. Sevilla: Ayuntamiento de Sevilla.

Rodríguez Baltanás, Enrique J. 1990. Flamenco y literatura. Alcalá de Guadaíra: Editorial Guadalmena.

Said, Edward. 2004. Orientalismo. Barcelona: DeBolsillo.

Santiago Lázaro, María Valentina de. 2006. La danza española como espectáculo cosmopolita. Ciudad de México 1939-1949. Tesis de licenciatura. UNAM. https://ru.dgb.unam.mx/handle/DGB UNAM/TES01000604617

Shade Venegas, Jessica. 2009. «Heterotopic Space and the Limits of Naturalist Discourse in Federico Gamboa's Santa». SYMPOSIUM, 63.4: 251-264.

Sierra, María. 2019. «Hombres arcaicos en tiempos modernos. La construcción romántica de la masculinidad gitana». Historia Social, 93: 51-65.

Steingress, Gerhard. 1990. «Preliminares». En Los cantes flamencos, Hugo Schuchardt. Sevilla: Fundación Machado, pp. 9-11.

—. 2005. «La hibridación transcultural como clave de la formación del nuevo flamenco. Aspectos histórico-sociológicos, analíticos y comparativos». Música oral del Sur, 6: 119-152.

-. 2006. «Silverio Franconetti en Uruguay. La aventura taurina del cantaor sevillano (1857-1864)». Revista de Estudios Taurinos, 22: 133-202.

Torres-Rioseco, Arturo. 1939. «Carlos Reyles». Revista Iberoamericana, 1.1: 339-351. http://revistaiberoamericana.pitt.edu/ojs/index.php/Iberoamericana/article/view/717/964

Visca, Arturo Sergio. 1992. «Los 70 años de El embrujo de Sevilla». Almanaque del Banco de Seguros del Estado. Montevideo: 105-110.

Zambrano, María y José Ortega y Gasset. 1984. Andalucía. Sueño y realidad. Granada: Biblioteca de la Cultura Andaluza.

Zum Felde, Alberto. 1941. Proceso intelectual del Uruguay y crítica de su literatura. Montevideo: Editorial Claridad. 